\title{
The content of chlorides in blast-furnace slag cement as a factor affecting the diffusion of chloride ions in concrete
}

\author{
Justyna Kuziak ${ }^{1,{ }^{*}}$, Piotr Woyciechowski ${ }^{1}$, Rafat Kobyłka ${ }^{2}$, and Aldona Wcisło $^{2}$ \\ ${ }^{1}$ Warsaw University of Technology, Al. Armii Ludowej 16, Warsaw 00-637, Poland \\ ${ }^{2}$ Institute of Agrophysics, Polish Academy of Sciences, Doświadczalna 4, Lublin 20-290, Poland
}

\begin{abstract}
Blast-furnace slag cement (CEM III) has a wide range of acceptable $\mathrm{Cl}^{-}$content according to EN 197-1: 2012. This makes possible to use alternative fuels for the production of cement, which can increase the chlorides content in the clinker. However, it raises several new research problems, among them the problem of increase of the risk of $\mathrm{Cl}^{-}$ penetration intensity due to the higher concentration of chlorides in cement, presented in this paper. Studies have shown that after a short hardening time (28 days) the rate of diffusion of chloride ions increases slightly with the increase in the content of chlorides in the cement CEM III, but after full stabilization of concrete properties ( 1 year), the content of chlorides in cement CEM III practically does not affect the diffusion rate of chloride ions in concrete.
\end{abstract}

\section{Introduction}

Chloride ions are one of the two main causes of corrosion of steel reinforcement in concrete. Because of the reason above, existing standards contain limitations of chloride ions content in concrete as well as its components. According to EN 197-1: 2012 [1], the acceptable content of chloride ions in cement is $0.1 \%$. The exception is blast-furnace slag cement (CEM III), which may contain more than $0.1 \%$ chlorides. The total $\mathrm{Cl}^{-}$content in concrete in Europe is limited by EN 206: 2013 [2] and is in range from 0.1 to 1.0 depending on the type of reinforcement.

The higher allowed content of $\mathrm{Cl}^{-}$in CEM III makes possible to use alternative fuels for the production of cement, which can increase the chlorides content in the clinker. However, it raises several new research problems, e.g.:

1) does the higher concentration of chlorides in cement affect the protective ability of concrete cover for reinforcement ?

2) does the higher concentration of chlorides in cement increase the risk of $\mathrm{Cl}^{-}$ penetration intensity?

The first problem was investigated in the Kuziak et al. [3], where influence of chloride ions content in cement type CEM III, in range $0.085-0.5 \%$, on steel reinforcement was

\footnotetext{
${ }^{*}$ Corresponding author: jkuziak@il.pw.edu.pl
} 
presented. Authors found no effect of chlorides content in the CEM III, over a range of tested values, on the corrosion of steel. Noncarbonated concrete cover, even at the highest chlorides content $(0.5 \%$ in cement), protected reinforcement from corrosion.

Research focused on the second problem - influence of chloride ions content in CEM III on the diffusion of chloride ions in concrete made with this cement - is presented in this paper.

The effective coefficient of chloride ions diffusion $\left(D_{\text {eff }}\right)$ is a measure of the rate of chlorides penetration into concrete. It depends primary on the composition of the cement (the ability to bind chloride ions by the cement matrix), the water/cement ratio and the age of the concrete. Concrete containing cement with ground granulated blast-furnace slag is characterized by low $D_{\text {eff }}$ and value of $D_{\text {eff }}$ decreases with the age of concrete [4]. To authors' knowledge there are no publication dealing with the effect of initial content of $\mathrm{Cl}^{-}$ in cement on chlorides diffusion in concrete.

\section{Materials and methods}

The chloride ions diffusion research was performed for concrete specimens with water/cement ratio 0.44 made of cements type CEM III A 42.4 with chlorides content of $0.1,0.2$ and $0.5 \%$. The tests were carried out after 28 days and after a year of concrete hardening. Samples were stored before tests in a climate chamber (temperature $=20 \pm 2^{\circ} \mathrm{C}$, $\mathrm{RH}>95 \%$ ).

Chlorides diffusion test for specimens after 28 days of hardening were carried out in a two-chamber vessel. These chambers, with volume of approx. $1.2 \mathrm{dm}^{3}$, were separated by concrete membrane $(120 \times 120 \times 25 \mathrm{~mm})$ (Fig. 1). One of the chambers was filled with a solution of $\mathrm{NaCl}$ with concentration $3 \%$ and the other one with distilled water. Chlorides diffused from the first chamber into the concrete. The concrete surface in contact with the solutions was ca. $81 \mathrm{~cm}^{2}$.

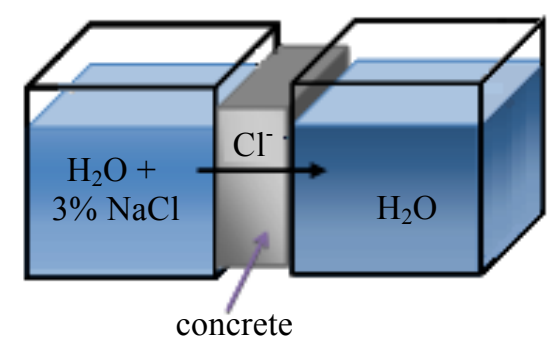

Fig. 1. The experimental set-up for the chlorides diffusion tests.

The concrete samples $(120 \times 120 \times 50 \mathrm{~mm})$ that hardened for a year were placed in a vessel filled with solution of $\mathrm{NaCl}$ with concentration $3 \%$, so that the samples were completely immersed in the solution.

After 29-32 days concrete specimens were removed and concrete samples from various depths for determination of chloride ions were taken using the Profile Grinder Kit. Thicknesses of the taken concrete layers were $1 \mathrm{~mm}$. Chloride ions determination was carried out using the Volhard's method. The determination of chlorides content in reference concrete (concrete not in contact with the $\mathrm{NaCl}$ solution) was also carried out.

The effective diffusion coefficient of chloride ions was determined by fitting the obtained values of chloride ions content in concrete to equation (1). 


$$
c=c_{0}\left[1-\operatorname{erf}\left(\frac{x}{2 \sqrt{D_{\text {gff }}}}\right)\right]
$$

where:

$c$ - chlorides content in concrete at depth $x$,

$c_{0}$ - chlorides content in the near-surface layer of concrete,

erf - error function,

$x$ - distance from the concrete surface,

$\mathrm{t}$ - time of chlorides diffusion in concrete.

To include the initial chlorides content in concrete (resulting from the chlorides content in all concrete components), calculation were also made for chlorides content after correction for the initial content (after subtraction the chlorides content in the reference samples that were not placed in the $\mathrm{NaCl}$ solution).

\section{Results}

The obtained results of the initial content of chloride ions in reference concrete and the content of chloride ions in concrete, to which chloride ions penetrated, are presented in Table 1-3 and Fig. 2. The chlorides penetration was lower in concrete tested after one year of hardening than in concrete tested after 28 days of hardening, which indicates the densification of the concrete microstructure over the time. In the case of samples that hardened for 28 days, a slight increase in the $D_{\text {eff }}$ (faster penetration of chlorides into the concrete) was observed (Table 4, Fig. 3) with an increase in the chlorides content in cement from which the concrete samples were made. Chlorides penetrating the concrete can be bound by hydrated calcium aluminates present in hardened cement matrix of concrete (2) [5].

$$
3 \mathrm{CaO} \cdot \mathrm{Al}_{2} \mathrm{O}_{3} \cdot 6 \mathrm{H}_{2} \mathrm{O}+2 \mathrm{Cl}^{-}+\mathrm{Ca}^{2+}+4 \mathrm{H}_{2} \mathrm{O} \rightarrow 3 \mathrm{CaO} \cdot \mathrm{Al}_{2} \mathrm{O}_{3} \cdot \mathrm{CaCl}_{2} \cdot 10 \mathrm{H}_{2} \mathrm{O}
$$

The slower penetration of chlorides into the concrete with a lower initial chlorides content may be associated with a greater ability to bind chlorides by hardened cement paste with a low chlorides content.

Also, the correction of the results by the initial chlorides content did not change the observed trend, however the increase of $D_{\text {eff }}$ was slower than in the case of calculations without correction (Table 4, Fig. 3).

After a year of hardening of the concrete, reduction in $D_{\text {eff }}$ was observed (Table 4, Fig. 4 ) - about two times in the case of samples made of cement containing $0.1 \%$ of chlorides and approx. 4-6 times in concrete with cement with a higher initial chlorides content.

Slower diffusion of chloride ions in older concrete is related to the concrete microstructure densification in time due to the hydration reactions of the binder components. This effect is particularly visible in the case of concrete with cement CEM III, which is characterized by a relatively low degree of hydration after 28 days. The dependence of $D_{\text {eff }}$ values on time describes the equation (3) [6]:

$$
D_{\text {eff }}=D_{\text {eff } 0}\left(\mathrm{t}_{0} / \mathrm{t}\right)^{\mathrm{m}}
$$

where $D_{\text {eff }}$ is the value of the effective diffusion coefficient determined on the basis of measurements at time $t_{0}$, and $m$ is a parameter characterizing the change in the diffusion coefficient over time. The value of $m$ depends mainly on the type of cement and water/cement ratio. Based on $D_{\text {eff }}$ values obtained after 28 days and one year of concrete hardening, the parameter $m$ is 0.3 for concrete made of cement with a chlorides content of $0.1 \%$ and $0.6-0.7$ for concrete made of cement with a higher initial chlorides content. The 
observed effect is consistent with literature data, according to which the $D_{\text {eff }}$ of chlorides in concrete with CEM III shows a significant decrease in time, and the obtained values of $m$ are from 0.27 to $0.8[6,7,8]$. In the case of concretes made of Portland cement, the changes in the diffusion coefficient over time are much lower (according to literature data $m$ is 0.1 0.25). This is related to the slower and longer hydration of cement type CEM III, which results in a slower increase in the strength of the concrete, as well as in the extension period of the concrete microstructure densification.

Table 1. The initial content of chloride ions in reference concrete to which chlorides did not penetrate.

\begin{tabular}{|c|c|c|c|}
\hline Concrete & $\begin{array}{c}\text { Concrete with CEM III } \\
\text { with } \mathrm{Cl}^{-} \text {content } \mathbf{0 . 1 \%}\end{array}$ & $\begin{array}{c}\text { Concrete with CEM III } \\
\text { with } \mathrm{Cl}^{-} \text {content } \mathbf{0 . 2 \%}\end{array}$ & $\begin{array}{c}\text { Concrete with CEM III } \\
\text { with } \mathrm{Cl}^{-} \text {content } \mathbf{= 0 . 5 \%}\end{array}$ \\
\hline$\% \mathrm{Cl}^{-}$in concrete & 0.02 & 0.03 & 0.07 \\
\hline
\end{tabular}

Table 2. The content of chloride ions in concrete after the diffusion test of chloride ions - after a 28 days of concrete hardening.

\begin{tabular}{|c|c|c|c|}
\hline $\begin{array}{l}\text { Depth, } \\
\text { mm }\end{array}$ & $\begin{array}{c}\% \mathrm{Cl}^{-} \text {in concrete with } \\
\mathrm{CEM} \text { III with } \mathrm{Cl}^{-} \text {content }= \\
0.1 \% \text { (after } 32 \text { days of } \mathrm{Cl}^{-} \\
\text {penetration) }\end{array}$ & $\begin{array}{c}\% \mathrm{Cl}^{-} \text {in concrete with } \\
\mathrm{CEM} \text { III with } \mathrm{Cl}^{-} \text {content } \\
=0.2 \% \text { (after } 32 \text { days of } \\
\mathrm{Cl}^{-} \text {penetration) }\end{array}$ & $\begin{array}{c}\% \mathrm{Cl}^{-} \text {in concrete with } \\
\mathrm{CEM} \text { III with } \mathrm{Cl}^{-} \text {content } \\
=0.1 \% \text { (after } 30 \text { days of } \\
\mathrm{Cl}^{-} \text {penetration) }\end{array}$ \\
\hline $0-1$ & $0.63 \pm 0.04$ & $0.60 \pm 0.19$ & $0.61 \pm 0.02$ \\
\hline $1-2$ & $0.44 \pm 0.02$ & $0.59 \pm 0.14$ & $0.48 \pm 0.01$ \\
\hline $2-3$ & $0.26 \pm 0.03$ & $0.37 \pm 0.08$ & $0.35 \pm 0.01$ \\
\hline $3-4$ & $0.17 \pm 0.02$ & $0.25 \pm 0.04$ & $0.26 \pm 0.01$ \\
\hline $4-5$ & $0.11 \pm 0.00$ & $0.17 \pm 0.02$ & $0.24 \pm 0.02$ \\
\hline $5-6$ & $0.06 \pm 0.01$ & $0.12 \pm 0.04$ & $0.19 \pm 0.03$ \\
\hline $6-7$ & $0.05 \pm 0.02$ & $0.08 \pm 0.02$ & $0.18 \pm 0.02$ \\
\hline $7-8$ & & & $0.16 \pm 0.00$ \\
\hline
\end{tabular}

Table 3. The content of chloride ions in concrete after the diffusion test of chloride ions - after a year of concrete hardening.

\begin{tabular}{|c|c|c|c|}
\hline $\begin{array}{l}\text { Depth, } \\
\text { mm }\end{array}$ & $\begin{array}{c}\% \mathrm{Cl}^{-} \text {in concrete with } \\
\mathrm{CEM}^{-} \mathrm{III} \text { with } \mathrm{Cl}^{-} \text {content } \\
=0.1 \% \text { (after } 29 \text { days of } \\
\mathrm{Cl}^{-} \text {penetration) }\end{array}$ & $\begin{array}{c}\% \mathrm{Cl}^{-} \text {in concrete with } \\
\mathrm{CEM} \text { III with } \mathrm{Cl}^{-} \text {content } \\
=0.2 \% \text { (after } 30 \text { days of } \\
\mathrm{Cl}^{-} \text {penetration) }\end{array}$ & $\begin{array}{c}\% \mathrm{Cl}^{-} \text {in concrete with } \\
\mathrm{CEM} \text { III with } \mathrm{Cl}^{-} \text {content } \\
=0.1 \% \text { (after } 30 \text { days of } \\
\mathrm{Cl}^{-} \text {penetration) }\end{array}$ \\
\hline $0-1$ & $0.47 \pm 0.15$ & $0.60 \pm 0.10$ & $0.42 \pm 0.20$ \\
\hline $1-2$ & $0.26 \pm 0.13$ & $0.27 \pm 0.01$ & $0.25 \pm 0.17$ \\
\hline $2-3$ & $0.13 \pm 0.10$ & $0.15 \pm 0.04$ & $0.14 \pm 0.08$ \\
\hline $3-4$ & $0.07 \pm 0.05$ & $0.07 \pm 0.00$ & $0.10 \pm 0.04$ \\
\hline $4-5$ & $0.06 \pm 0.04$ & $0.04 \pm 0.01$ & $0.08 \pm 0.01$ \\
\hline $5-6$ & $0.03 \pm 0.01$ & $0.03 \pm 0.00$ & $0.07 \pm 0.01$ \\
\hline $6-7$ & $0.02 \pm 0.01$ & $0.03 \pm 0.01$ & $0.08 \pm 0.01$ \\
\hline $7-8$ & $0.02 \pm 0.00$ & $0.02 \pm 0.00$ & $0.07 \pm 0.00$ \\
\hline $8-9$ & $0.02 \pm 0.00$ & $0.02 \pm 0.01$ & $0.08 \pm 0.00$ \\
\hline $9-10$ & $0.01 \pm 0.00$ & $0.02 \pm 0.00$ & $0.08 \pm 0.00$ \\
\hline
\end{tabular}

Table 4. The dependence of the effective diffusion coefficient of chlorides in concrete on the initial content of chlorides in the cement.

\begin{tabular}{|c|c|c|c|c|}
\hline Age of concrete & \% CI in CEM III & $\mathbf{0 . 1}$ & $\mathbf{0 . 2}$ & $\mathbf{0 . 5}$ \\
\hline \multirow{2}{*}{28 days } & $D_{\text {eff }} 10^{-12} \mathrm{~m}^{2} / \mathrm{s}$ & $\mathbf{1 . 7} \pm 0.4$ & $\mathbf{3 . 2} \pm 0.7$ & $\mathbf{5 . 4} \pm 1.7$ \\
\cline { 2 - 5 } & $D_{\text {eff corrected }}{ }^{-1} 10^{-12} \mathrm{~m}^{2} / \mathrm{s}$ & $\mathbf{1 . 5} \pm 0.4$ & $\mathbf{2 . 6} \pm 0.6$ & $\mathbf{3 . 5} \pm 1.0$ \\
\hline \multirow{2}{*}{1 year } & $D_{\text {eff, }} 10^{-12} \mathrm{~m}^{2} / \mathrm{s}$ & $\mathbf{0 . 9} \pm 0.4$ & $\mathbf{0 . 7} \pm 0.1$ & $\mathbf{1 . 3} \pm 0.6$ \\
\cline { 2 - 5 } & $D_{\text {eff corrected }}{ }^{1)} 10^{-12} \mathrm{~m}^{2} / \mathrm{s}$ & $\mathbf{0 . 8} \pm 0.4$ & $\mathbf{0 . 5} \pm 0.1$ & $\mathbf{0 . 6} \pm 0.4$ \\
\hline
\end{tabular}

${ }^{1)} D_{\text {eff }}$ calculation based on chlorides content in concrete after correction for initial chlorides content. 
After the correction of results for the initial content of chlorides in the concrete, similar $D_{\text {eff }}$ values were obtained in all tested samples, which indicates no significant influence of the initial content of chloride ions in the cement type CEM III on the diffusion rate of chloride ions in concrete. Therefore, the factor determining the rate of penetration of chloride ions into concrete made of CEM III after a year of hardening is the age of concrete and the associated concrete microstructure densification.

A)

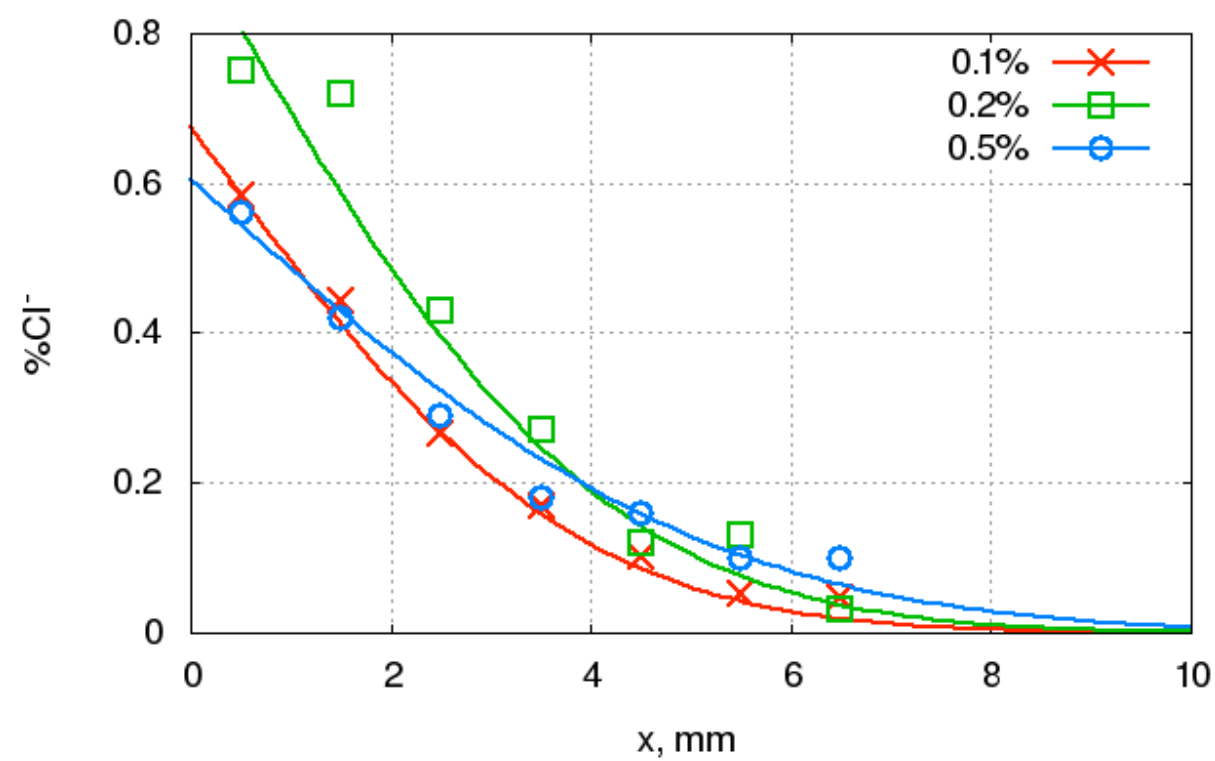

B)

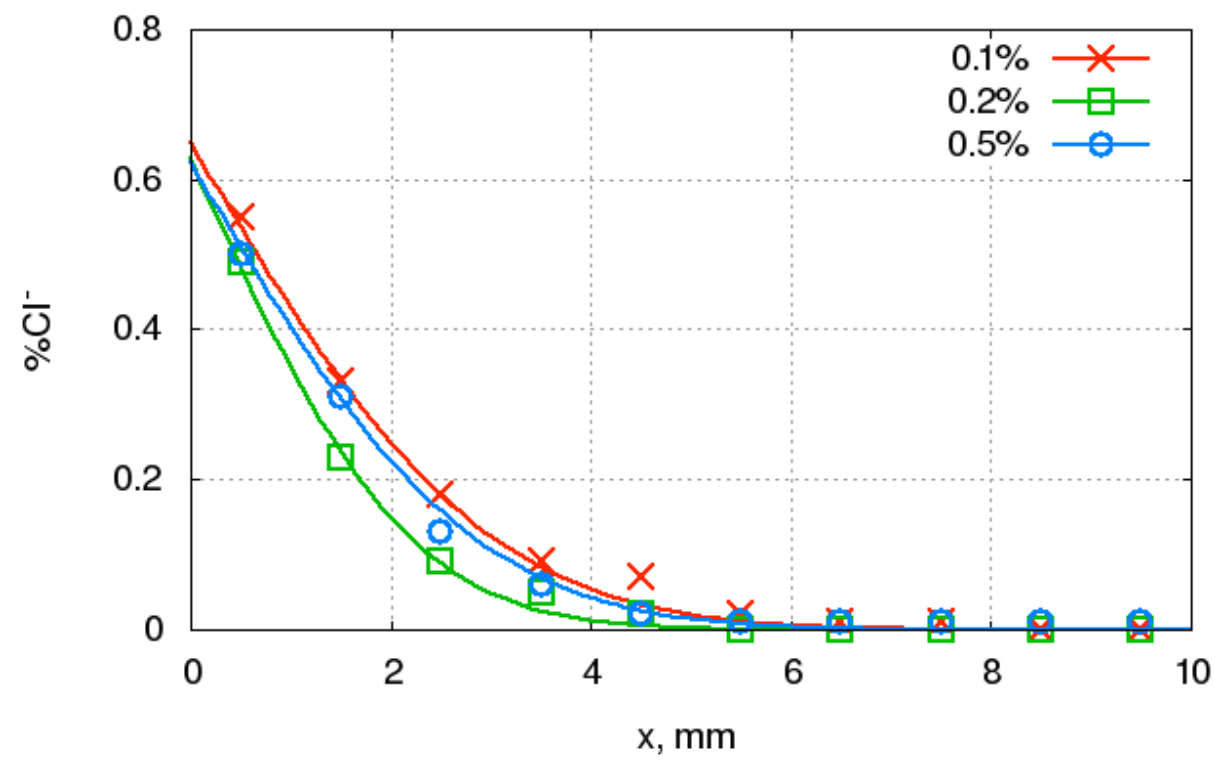

Fig. 2. Dependence of chlorides content in concrete made of cement CEM III containing 0.1, 0.2 and $0.5 \%$ chlorides, on the concrete depth (points) fitted to equation (1) (lines). A) after 28 days, B) after one year of hardening of concrete. Results after correction for initial chlorides content in concrete. 


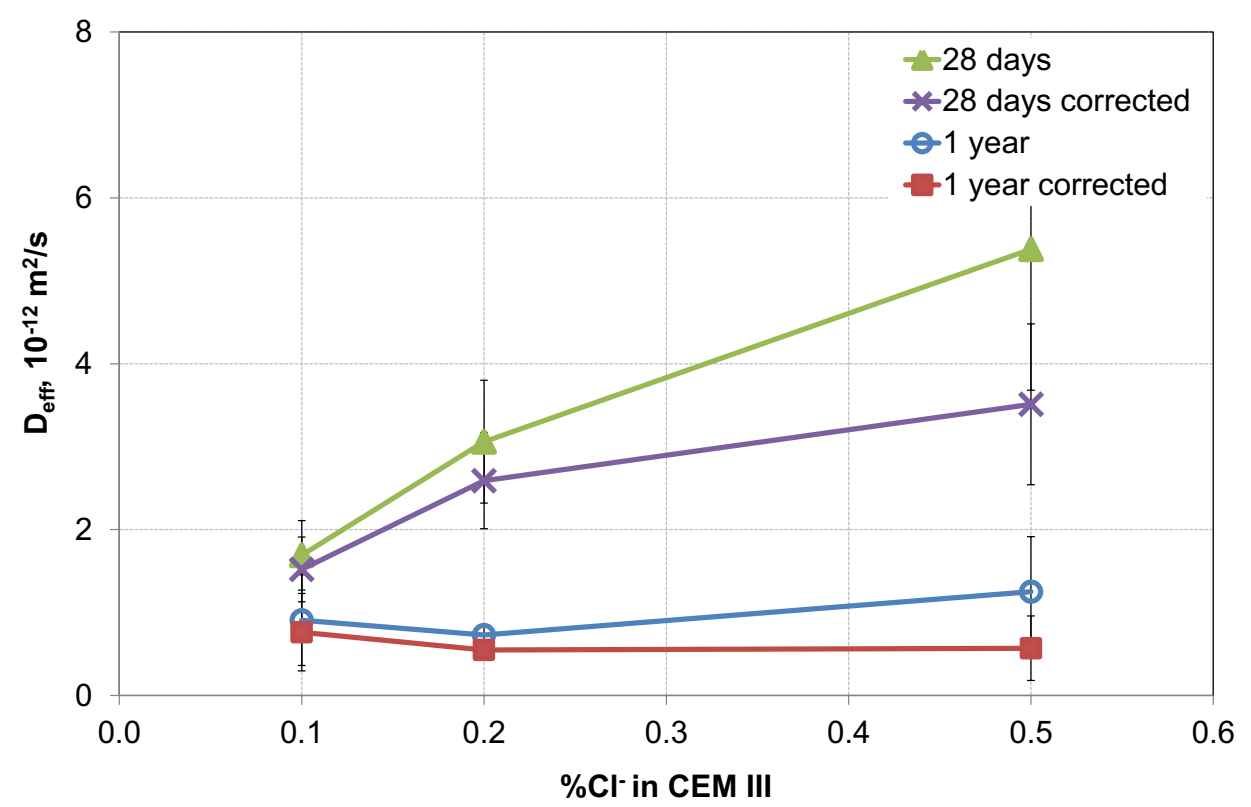

Fig. 3. Change of the effective diffusion coefficient of chlorides in concrete with cement CEM III with chlorides content $0.1,0.2$ and $0.5 \%$.

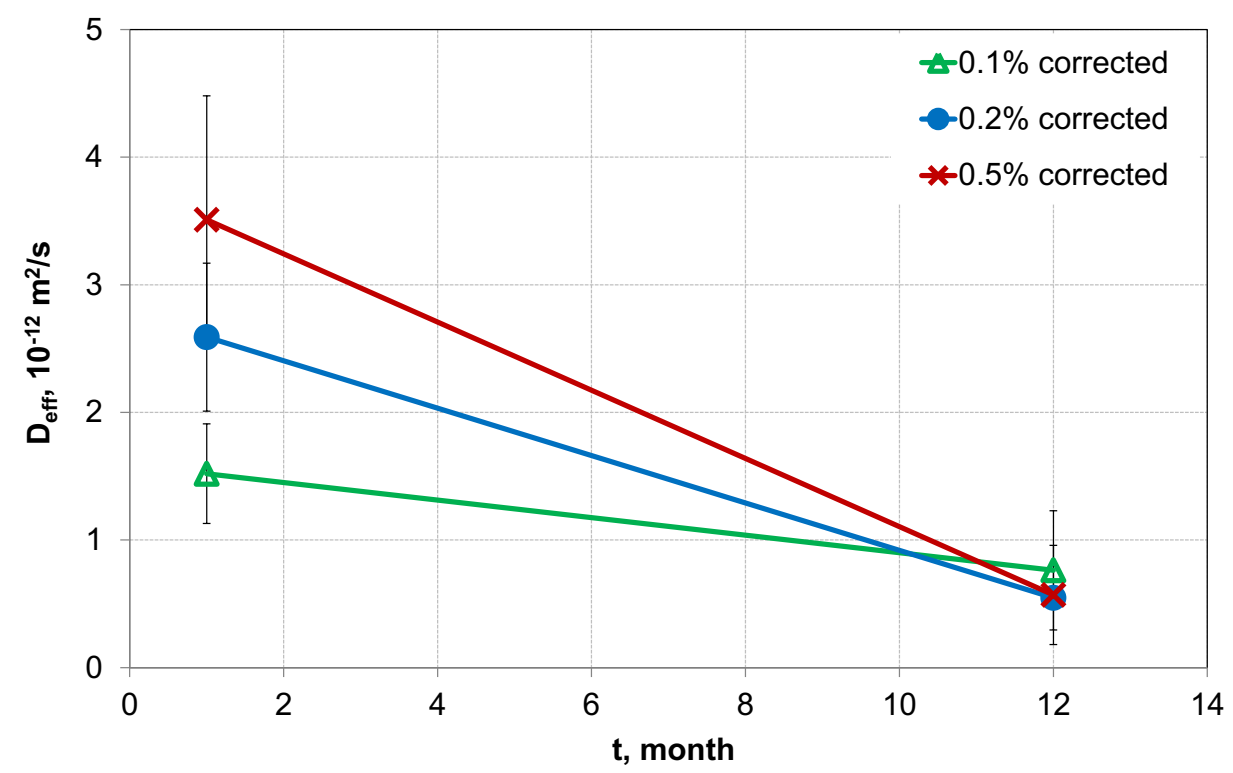

Fig. 4. Time dependence of the effective diffusion coefficient of chlorides in concrete made of cement type CEM III containing $0.1,0.2$ and $0.5 \% \mathrm{Cl}^{-}$. Results after correction for initial chlorides content in concrete. 


\section{Conclusions}

On the basis of conducted investigations, the following conclusions were found out:

1. After a short hardening time (28 days) the rate of diffusion of chloride ions in concrete made of cement type CEM III increases slightly with the increase in the content of chlorides in the cement, but after full stabilization of concrete properties (1 year), the content of chlorides in cement CEM III practically does not affect the diffusion rate of chloride ions in concrete.

2. The age of concrete affects the diffusion rate of chloride ions. With the elongation of the hardening time from one month to one year, $D_{\text {eff }}$ decreased - from 2 to 6 times depending on the content of $\mathrm{Cl}^{-}$in cement.

3. The higher $\mathrm{Cl}^{-}$content in concrete results in stronger influence of hardening time on $D_{\text {eff }}$ value, but when $\mathrm{Cl}^{-}$content is higher than $0.2 \%$ - differences between $D_{\text {eff }}$ values are small. Calculated values of parameter $m$ are as follows: 0.25 for $\mathrm{Cl}^{-}$content equal to $0.1 \%$ and $0.6-0.7$ for $\mathrm{Cl}^{-}$content as high as $0.2-0.5 \%$.

\section{References}

1. EN 197-1 (2012)

2. EN 206 (2013)

3. J. Kuziak, P. Woyciechowski, A. Wcisło, Corr. Prot. 59, 169 (2016)

4. K.Y. Yeau, E.K. Kim, Cem. Concr. Res. 35 ,1391 (2005)

5. W. Kurdowski, Cement and concrete chemistry (Springer Science \& Business, 2014)

6. D.H. Chisholm, N.P. Lee, $20^{\text {th }}$ Biennial Conference of the Concrete Institute of Australia, 96 (2001)

7. J.E. Carlsen, $2^{\text {nd }}$ International RILEM Workshop on Testing and Modelling the Chloride Ingress into Concrete, 161 (2000)

8. P.B. Bamforth, Mag. of Concr. Res. 51, 87 (1999) 
